\title{
Hydro-Upgrading of Algal Biocrude in Tetralin for the Production of High-Quality Liquid Fuel: Process Intensification
}

\author{
Lei Chen ${ }^{1}$, Lin-Xin Yin ${ }^{1}$, Pei-Gao Duan ${ }^{1}$, Zhi-Cong Wang ${ }^{2}$, and Zhi-Xiang Xu ${ }^{3}$ \\ ${ }^{1}$ Xi'an Jiaotong University \\ ${ }^{2}$ Xian Jiaotong University \\ ${ }^{3}$ Affiliation not available
}

November 15, 2020

\begin{abstract}
Herein, we report a new process for intensified hydro-upgrading of a biocrude produced from the hydrothermal processing of Auxenochlorella pyrenoidosa (AuP) in tetralin at a mass ratio of $1: 1$ with the addition of $10 \mathrm{wt} . \% \mathrm{Pt} / \mathrm{C}$ and $8 \mathrm{MPa} \mathrm{H} 2$ at different temperatures $\left(300-480{ }^{\circ} \mathrm{C}\right)$ and times $(1-8 \mathrm{~h})$. Under the selected reaction conditions, the gaseous products were replaced with fresh $\mathrm{H} 2$ at regular time intervals; this process was then continued until the total reaction time was over. Increasing the number of $\mathrm{H} 2$ replacement times decrease the $\mathrm{C}, \mathrm{N}, \mathrm{O}$, and $\mathrm{S}$ contents and increased the $\mathrm{H}$ content. The treated bio-oil mainly consisted of aromatic, saturated and unsaturated hydrocarbons. Overall, H2 replacement removed some of the denitrogenation, desulfurization, and deoxygenation products and avoided secondary reactions of gaseous products with the bio-oil, thus promoting the hydrogenation reaction and $\mathrm{N}, \mathrm{O}$, and $\mathrm{S}$ removal from the treated bio-oil.
\end{abstract}

Hydro-upgrading of algal biocrude in tetralin for the production of high-quality liquid fuel:process intensification

\section{Lei Chen ${ }^{1}$, Lin-Xin Yin ${ }^{1}$, Pei-Gao Duan ${ }^{1}$, ${ }^{*}$ Zhi-Cong Wang ${ }^{1}$, Zhi-Xiang $\mathrm{Xu}^{2}$,*}

${ }^{1}$ Shaanxi Key Laboratory of Energy Chemical Process Intensification, School of Chemical Engineering and Technology, Xi'an Jiaotong University, Xi'an, Shaanxi, 710049, P.R. China.

${ }^{2}$ School of Energy and Power Engineering, Jiangsu University, Zhenjiang 212013, China

\section{ABSTRACT}

Herein, we report a new process for intensified hydro-upgrading of a biocrude produced from the hydrothermal processing of Auxenochlorella pyrenoidosa (AuP) in tetralin at a mass ratio of 1:1 with the addition of $10 \mathrm{wt} . \%$ $\mathrm{Pt} / \mathrm{C}$ and $8 \mathrm{MPa} \mathrm{H}_{2}$ at different temperatures $\left(300-480{ }^{\circ} \mathrm{C}\right)$ and times $(1-8 \mathrm{~h})$. Under the selected reaction conditions, the gaseous products were replaced with fresh $\mathrm{H}_{2}$ at regular time intervals; this process was then continued until the total reaction time was over. Increasing the number of $\mathrm{H}_{2}$ replacement times decrease the $\mathrm{C}, \mathrm{N}, \mathrm{O}$, and $\mathrm{S}$ contents and increased the $\mathrm{H}$ content. The treated bio-oil mainly consisted of aromatic, saturated and unsaturated hydrocarbons. Overall, $\mathrm{H}_{2}$ replacement removed some of the denitrogenation, desulfurization, and deoxygenation products and avoided secondary reactions of gaseous products with the bio-oil, thus promoting the hydrogenation reaction and N, O, and S removal from the treated bio-oil.

Keywords: Microalgae; hydrothermal liquefaction; biocrude; hydro-upgrading; $\mathrm{H}_{2}$ replacement; treated biooil

${ }^{*}$ Corresponding author. Tel: +86-029-82665836/+86-029-3987823; Email address: pgduan@xjtu.edu.cn (P.-G Duan); xuzx@ujs.edu.cn (Z.X.Xu) 


\section{Introduction}

Microalgae are an alternative and promising way to solve the energy crisis and environmental pollution caused by the extensive utilization of fossil fuels due to their widespread availability, high efficiency of photosynthesis, short growth cycle, easy adaptation to the environment, large biomass production per acre and carbon neutrality ${ }^{1,2}$. Thermochemical conversion is one of the most promising and efficient ways to realize energy utilization with microalgae ${ }^{3,4}$, among which hydrothermal processing (e.g., hydrothermal liquefaction (HTL), hydrothermal carbonization, and hydrothermal gasification) is one of the most popularly employed methods because it can directly use high-moisture microalgae as feedstock ${ }^{5}$. During the HTL process, all the biochemical components, such as lipids, proteins and carbohydrates, contained in the microalgae can be simultaneously converted and transferred into an energy-dense material, biocrude ${ }^{5}$, thus using as much of the organic matter in the microalgae as possible.

However, large proportions of nitrogen $(\mathrm{N})$, sulfur $(\mathrm{S})$, and oxygen $(\mathrm{O})$ in the microalgae are converted into the biocrude during the HTL process, resulting in the biocrude having high concentrations of $\mathrm{N}$, O, and S. Therefore, catalysts were directly added during the HTL of microalgae, aiming to reduce the N, O, and S concentrations of the biocrude in situ. Unfortunately, poor catalyst performance regarding the removal of $\mathrm{N}, \mathrm{O}$, and $\mathrm{S}$ was observed ${ }^{6}$. Biocrude with a high oxygen content will lead to a high total acid number, high viscosity, low calorific value, and poor stability. Furthermore, biocrudes with high $\mathrm{N}$ and $\mathrm{S}$ contents will lead to significant quantities of nitrogen oxides and sulfur oxides when burned, causing environmental pollution. Therefore, algal biocrude needs to be further treated to address its several disadvantages prior to use.

To date, many techniques have been used to improve the quality of algal biocrudes, among which hydrotreatment is one of the most effective; most of these techniques involve one-pot treatment of the whole biocrude ${ }^{7}$ in the presence of a catalyst, high-pressure hydrogen, and sometimes a reaction medium. Li and Savage ${ }^{8}$ investigated the hydrotreatment of algal biocrude in the absence of a medium. The advantages of this process mainly include no need for additional medium and no hydrogen partial pressure during the reaction, while the disadvantages are also obvious, such as easy coke deposition, fast catalyst deactivation, and difficulty in reducing the $\mathrm{N}$ content of the product oil. The $\mathrm{N}$ content of the treated bio-oil remained at $1.6 \mathrm{wt} . \%$ after optimization of the reaction conditions. Many researchers have carried out hydrotreatment of biocrudes derived from different biomass feedstocks in different organic media ${ }^{9-11}$. The reaction medium selected for hydrotreatment of algal biocrude in the early stage was water because water has many advantages, such as cleanliness, good heat and mass transfer properties and being inexpensive and easy to obtain. Duan and Savage ${ }^{12-15}$, Duan et al. ${ }^{16}$, Xu et al. ${ }^{17}$, and Bai et al. ${ }^{18}$ studied the hydrotreatment of algal biocrude in supercritical water. The results indicated that supercritical water could suppress coke formation, and noble metals such as $\mathrm{Pt}, \mathrm{Pd}, \mathrm{Ru}$, Ir, and $\mathrm{Rh}$ showed high performance toward denitrogenation, while molybdenum-based catalysts such as $\mathrm{Mo}_{2} \mathrm{C}$ and $\mathrm{MoS}_{2}$ showed better performance toward deoxygenation and desulfurization. Under optimal conditions, the $\mathrm{N}$ content could be reduced from $4.8 \mathrm{wt} . \%$ in the biocrude to $1.5 \mathrm{wt} . \%$ in the treated bio-oil, and the effective hydrogen value $(\mathrm{H} / \mathrm{C})_{\mathrm{eff}^{19}}$ could be increased from 1.43 in the algal biocrude to 1.71 in the treated bio-oil. However, the disadvantage of using water as the reaction medium is that water can react with the bio-oil and raise the $\mathrm{O}$ content of the final treated bio-oil ${ }^{9}$. In contrast, hydrogen-donor solvents show considerable promise for the hydrotreatment of biocrude as they can not only dilute the biocrude and decrease the viscosity of the feedstock but also transform molecular hydrogen into active hydrogen and improve the hydrogenation efficiency of the feedstock ${ }^{10}$.

Recently, a two-stage process was adopted by Yang et $\mathrm{al}^{20}$ to enhance $\mathrm{N}$ and $\mathrm{O}$ removal from algal biocrude via hydrotreatment in the absence of a medium. That is, biocrude generated from the HTL of microalgae was first processed at $360{ }^{\circ} \mathrm{C}$ with added $\mathrm{Ni} / \mathrm{Mo} / \gamma-\mathrm{Al}_{2} \mathrm{O}_{3}$ and $4 \mathrm{MPa} \mathrm{H}_{2}$. The treated bio-oil collected during the first round of the upgrading process was used as the feedstock for the second round of upgrading under the same reaction conditions as the first run. This approach of two consecutive hydrotreatments of the algal biocrude effectively reduced the $\mathrm{N}, \mathrm{S}$, and $\mathrm{O}$ contents of the final treated bio-oil and increased the $(\mathrm{H} / \mathrm{C})_{\text {eff }}$ value from 1.47 in the biocrude to 1.62 in the treated bio-oil separated from the first-round upgrading process and 1.85 in the treated bio-oil separated from the second-round upgrading process. These interesting results provided 
inspiration: the equilibrium of denitrogenation, deoxygenation, and desulfurization reactions was broken in this two-stage batch hydrotreatment process of algal biocrude as the denitrogenation, deoxygenation, and desulfurization products were removed when the reactor was opened after the first round of treatment, avoiding the occurrence of secondary reactions of these products with the bio-oil.

Therefore, in the present study, we designed a new process to break the equilibrium of denitrogenation, deoxygenation, and desulfurization in algal biocrude upgrading to substantially decrease the $\mathrm{N}$, $\mathrm{O}$, and $\mathrm{S}$ concentrations of the final treated bio-oil. At a given temperature, the algal biocrude was dissolved in tetralin and hydrotreated with added catalyst and pressurized $\mathrm{H}_{2}$ for a period of time. Then, the reactor was cooled to room temperature, the gaseous products in the reactor were vented, and the reactor was charged with highpressure fresh $\mathrm{H}_{2}$. The reactor loaded with fresh $\mathrm{H}_{2}$ was operated for another period of time and then cycled down when needed. After several rounds of runs, the N, O, and S contents in the treated bio-oil could be significantly reduced. Pt/C (Pt, $10 \mathrm{wt} . \%)$ was used as the upgrading catalyst as it showed high performance toward the $\mathrm{N}, \mathrm{O}$, and $\mathrm{S}$ removal from the algal biocrude ${ }^{13,14}$. Tetralin was used as the reaction medium to enhance the hydrogenation reaction and made the separation of treated bio-oil easier by enabling the use of centrifugal separation instead of solvent extraction, whose superiorities had been evidenced when used as a reaction medium for hydrotreatment of straw bio-oil fraction. The influence of temperature $\left(300-480{ }^{\circ} \mathrm{C}\right)$, reaction time (1-8 h), and frequency of $\mathrm{H}_{2}$ replacement (for a given reaction time) on the product distribution and characteristics of the treated bio-oil were examined. Finally, the chemical compositions of treated bio-oil were characterized by elemental analysis and comprehensive two-dimensional gas chromatography-time-offlight mass spectrometry $(\mathrm{GC} \times \mathrm{GC}-\mathrm{TOF}-\mathrm{MS})$. Physical properties such as density, viscosity, moisture, total acid number, and freezing point of the treated oil were also tested.

\section{Experimental}

\section{Materials}

The microalga Auxenochlorella pyrenoidosa $(\mathrm{AuP})$ was used as feedstock for the production of biocrude and was purchased from Tianjian Biotechnology Co., Ltd. (Binzhou, Shandong, North China). The received AuP was heated in an oven at $110{ }^{\circ} \mathrm{C}$ for $12 \mathrm{~h}$ to remove moisture, pulverized to a particle size of 100 mesh and stored in a vacuum desiccator. Table 1 provides the proximate and ultimate analysis of $\mathrm{AuP}$. Pt/C was purchased from Zhengzhou Alfachem Co., Ltd. (Zhengzhou, Henan, China) and received at a moisture content of $\sim 65$ wt. $\%$ to avoid spontaneous combustion. This high-moisture $\mathrm{Pt} / \mathrm{C}$ catalyst was processed at 80 ${ }^{\circ} \mathrm{C}$ for $12 \mathrm{~h}$ in a vacuum drying oven prior to analysis and use. The $\mathrm{Pt} / \mathrm{C}$ had $10 \mathrm{wt} . \% \mathrm{Pt}$, a particle size of 200 mesh, and a specific surface area of $1200 \mathrm{~m}^{2} / \mathrm{g}$. High-purity tetralin ([?]99.5\%) was obtained from Aladdin Co., Ltd. (Shanghai, China) and used as received without any further treatment. Ultrapure water prepared in the lab was used for the HTL of AuP.

A GS1L-type stainless-steel batch reactor with a magnetic mixer was employed to conduct the HTL of microalgae. The total internal volume of this reactor was $1000 \mathrm{~mL}$, with rated temperatures and pressures of $400 \mathrm{degC}$ and $25 \mathrm{MPa}$, respectively. An electrical heater jacket with a power of $3 \mathrm{~kW}$ was used to heat the reactor. A photo of this GS1L reactor is provided in Fig. S1(a).

A $60 \mathrm{~mL}$ mini stainless-steel batch reactor with a rated temperature and pressure of $500 \mathrm{degC}$ and $40 \mathrm{MPa}$ was employed to conduct the hydrotreatment experiments, and no mixer was installed due to its limited internal space. This mini reactor was heated with a molten-salt bath consisting of $\mathrm{KNO}_{3}$ and $\mathrm{NaNO}_{3}$ at a mass ratio of 5:4. A photo of this mini reactor and the molten-salt batch is provided in Fig. S1(b). The two batch reactors were treated with supercritical water at $400 \operatorname{deg} \mathrm{C}$ for $4 \mathrm{~h}$ before use to ensure that the organic impurities in the reactors were totally removed and reactor wall catalysis was deactivated.

Methods

Hydrothermal liquefaction

A total of $100 \mathrm{~g}$ of AuP and $200 \mathrm{~g}$ of ultrapure water were added into the $1000 \mathrm{~mL}$ reactor and sealed. Nitrogen was used to flush the residual air in the head space of the reactor. The reaction was initiated by 
connecting a power source. The mixer speed was set at $600 \mathrm{r} / \mathrm{min}$. Approximately $80 \mathrm{~min}$ later, the reactor temperature reached $350 \mathrm{degC}$, and the time was set to zero at this point. The temperature was controlled at 350+-3 degC by an Omega temperature controller using a thermocouple inserted into a thermal well on the top cover of the reactor. The reaction time was $60 \mathrm{~min}$. The reaction pressure changed between 19 and $20 \mathrm{MPa}$ during the whole HTL process. After the reaction was completed, the reactor was removed from the electrical heater jacket and placed into an ice water bath to cool to room temperature. The gaseous products in the reactor were vented prior to opening. The oil phase, water phase, and solid residue could be easily separated due to their different densities. The separated biocrude was subjected to centrifugal separation at a speed of $12000 \mathrm{r} / \mathrm{min}$ to isolate the residual water and scum. This algal biocrude was stored in a refrigerator for subsequent use.

\section{Hydrotreatment of algal biocrude}

In an example experiment, $5.0 \mathrm{~g}$ of algal biocrude, $5.0 \mathrm{~g}$ of tetralin, and $0.5 \mathrm{~g}$ of $\mathrm{Pt} / \mathrm{C}$ were fully mixed and charged into the $60 \mathrm{~mL}$ mini stainless-steel batch reactor, which was tightly sealed. $\mathrm{H}_{2}$ was used to flush the reactor head space to eliminate the residual air and then charged to $8 \mathrm{MPa}$, which was in excess of the amount required for the complete removal of $\mathrm{N}, \mathrm{O}$, and $\mathrm{S}$ in the biocrude. During the hydrotreatment process, tetralin could also be hydrogenated to naphthane with added $\mathrm{Pt} / \mathrm{C}^{10}$. Therefore, we assumed that all the loaded hydrogen was completely consumed by the algal biocrude and tetralin to calculate the gas yield after the reaction. The loaded reactor was put into the preheated molten-salt bath so as to submerge the reactor body. A thermocouple, which was connected to a temperature controller, was inserted into the thermal well on the top cover of the reactor to control the temperature. The preheating time varied from 5 to 15 min depending on the reaction temperature. After the completion of the reaction time, the reactor was removed from the molten-salt bath and put into an ice water bath to cool to room temperature. The gaseous product weight was quantified from the weight difference before and after gas exhaust. The reaction mixture was subjected to centrifugal filtration at a speed of $12000 \mathrm{rpm}$. The solid residue and catalyst remained in the filter basket, which was dried at $105 \operatorname{degC}$ for $12 \mathrm{~h}$ and weighed. The weight of the solid residue was obtained by subtracting the catalyst's weight. The liquid remaining at the bottom of the centrifuge tube was the treated bio-oil. The collected treated bio-oil was weighed and stored in a refrigerator for further characterization. The yields of treated bio-oil, solid residue, and gas were estimated using their mass divided by the mass of the feedstock (biocrude+tetralin) charged into the reactor.

For the hydrogen replacement experiment, once the selected reaction time was over, the reactor was moved out of the molten-salt bath and put into an ice water bath to cool to room temperature. The gas in the reactor was ventilated and then charged with fresh hydrogen to $8 \mathrm{MPa}$. The goal of this process was to remove the denitrogenation, deoxygenation, and desulfurization products from the reactor and avoid their secondary reactions with the oil. Since the hydrogen was assumed to be completely consumed in the first round of the hydrotreatment process, the fresh hydrogen loaded into the second-round reaction was assumed to not be consumed. Therefore, the real gas weight produced in the second round was calculated by subtracting the amount of fresh $\mathrm{H}_{2}(\sim 0.258 \mathrm{~g})$ charged into the reactor. This freshly $\mathrm{H}_{2}$-charged reactor was placed into the molten-salt bath again at the same temperature as that of the first stage for another period of time, and then the $\mathrm{H}_{2}$ replacement process was repeated. Once the total reaction time was over, the reactor was moved out of the molten-salt bath and placed into the ice water bath to cool to room temperature. The subsequent procedure for product recovery was the same as that described above for the first round.

\section{Catalyst characterization}

The morphology images of the as-prepared sample were obtained on a field-emission scanning transmission electron microscope (Zeiss GeminiSEM 500). Transmission electron microscopy (TEM), high-angle annular dark-field scanning TEM (HAADF-STEM) and energy-dispersive X-ray spectrometry (EDS) analysis were taken using a Field Emission Transmission Electron Microscope under 200 kV (ThermoFisher Talos-F200X). The surface compositions of samples were collected by a Kratos spectrometer (AXIS Ultra DLD) photoelectron spectrometer with a monochromatic $\mathrm{Al} \mathrm{K} \alpha(1486.6 \mathrm{eV}) \mathrm{X}$-ray source, and the shift of binding energy was calibrated using the $\mathrm{C} 1 \mathrm{~s}$ level at $284.6 \mathrm{eV}$ as an internal standard. 
Product analysis

A Thermo Fisher Scientific FLASH 2000 organic elemental analyzer (Thermo Fisher Scientific, Waltham, MA, USA) was used to quantify the $\mathrm{C}, \mathrm{H}$, and $\mathrm{O}$ contents in the alga, algal biocrude, and treated bio-oils. A TN-3000 chemiluminescence nitrogen analyzer and TS-3000 fluorescence sulfur analyzer (TNS-3000 N, S autoanalyzer, Jiangsu Guochuang Analytical Instrument Co., Ltd., China) were employed to confirm the N and $\mathrm{S}$ contents in the treated bio-oil as their concentrations were beyond the detection limit of the organic elemental analyzer. The higher heating value (HHV) was calculated by using the Dulong formula:

$\mathrm{HHV}(\mathrm{MJ} / \mathrm{kg})=0.338 \times \mathrm{C}+1.428 \times(\mathrm{H}-\mathrm{O} / 8)+0.095 \times \mathrm{S}$

where $\mathrm{C}, \mathrm{H}, \mathrm{O}$, and $\mathrm{S}$ represent the weight contents of the corresponding elements in the sample.

GC $\times$ GC-TOF-MS (LECO Pegasus-IV, LECO, USA) was used to analyze the molecular composition of the algal biocrude and treated bio-oils. Two columns were installed in this GC $\times$ GC-TOF-MS system. The first column was a middle-polar VF-17 MS column $(30 \mathrm{~m} \times 0.25 \mathrm{~mm}$ ID $\times 0.25 \mu \mathrm{m}$ film thickness $)$ that separates compounds based on their boiling points. The second column was a nonpolar Rxi-1 MS column (1.79 $\mathrm{m} \times$ $0.15 \mathrm{~mm}$ ID $\times 0.15 \mu \mathrm{m}$ film thickness) that separates compounds based on their polarity. Dichloromethane was used to dilute the oil samples at a concentration of $20 \mathrm{wt} . \%$. One microliter of sample was injected each time. The inlet temperature was $300{ }^{\circ} \mathrm{C}$, and the inlet was operated in spitless mode. A $240 \mathrm{~s}$ solvent delay was used to protect the filament. He at a flow rate of $1 \mathrm{~mL} / \mathrm{min}$ served as the carrier gas. The ion source and transmission wire temperatures were $250{ }^{\circ} \mathrm{C}$ and $280{ }^{\circ} \mathrm{C}$, respectively. For the one-dimensional oven temperature program, the temperature was held at $40{ }^{\circ} \mathrm{C}$ for $3 \mathrm{~min}$, then raised to $280{ }^{\circ} \mathrm{C}$ at $4{ }^{\circ} \mathrm{C} / \mathrm{min}$ and held for $3 \mathrm{~min}$. The mass spectrometry acquisition rate was 100 spectra per second. Each compound was selected from the 10 most similar substances from mainlib and replib for identification. Substances were positively identified with a similarity of 700 or more.

The gas composition after the hydrotreatment reaction was also qualified by the GC $\times$ GC-TOF-MS system as mentioned above. The gas sample was injected using a microsyringe injector. For the one-dimensional oven temperature program, the temperature was held at $40{ }^{\circ} \mathrm{C}$ for $2 \mathrm{~min}$, raised to $280{ }^{\circ} \mathrm{C}$ at $16{ }^{\circ} \mathrm{C} / \mathrm{min}$ and held for $1 \mathrm{~min}$. The other parameters were the same as in the oil analysis.

A GC-7900 gas chromatograph (Shanghai Techcomp Scientific Instrument Co., Ltd.) was used to quantify the ammonia in the gaseous products. A stainless-steel packed ammonia analysis column was used to separate the gas components. A constant inlet temperature of $120{ }^{\circ} \mathrm{C}$ and oven temperature of $60{ }^{\circ} \mathrm{C}$ were used. Argon served as the carrier gas at a flow rate of $15 \mathrm{~mL} / \mathrm{min}$. The filament current of the thermal conductivity detector (TCD) was set at $50 \mathrm{~mA}$, and the inlet pressure was $0.20 \mathrm{MPa}$.

The density of the algal biocrude and treated bio-oil was tested by evaluating the weight of one milliliter of sample at $25^{\circ} \mathrm{C}$. The total acid number (TAN) and moisture contents were determined according to Ref. ${ }^{21}$ The viscosity of the algal biocrude and treated bio-oil was determined using NDJ-8S rotary viscometer (Shanghai Changji Geological Instrument Co. LTD, Shanghai, China) at $25{ }^{\circ} \mathrm{C}$ according to ASTM D7042-20. ${ }^{22}$ The freezing point of the algal biocrude and treated bio-oil was estimated using BCQ-600B tester (Shandong Benchuan Instrument Co., LTD, Zibo, Shandong province, China) according to ASTM D2386-19. ${ }^{23}$

\section{Results and discussion}

Characterization of the $\mathrm{Pt} / \mathrm{C}$

The micromorphology of the prepared Pt/C nanomaterial was further characterized by the FE-SEM and TEM measurements. As showed in Fig 1 (a, b), the as-obtained Pt/C sample presented the morphology of nanoparticles with the size of 50-100 nm. TEM image confirms the particle-like structure of the as-prepared sample (Fig. 1c). The bright spots in the STEM images (Fig. 1d) demonstrated that the platinum particles of ultrafine size were tightly anchored on the AC support. Moreover, the EDS elemental mapping analysis (Fig. 1e and f) evidenced that the $\mathrm{Pt}$ and $\mathrm{C}$ elements were homogeneously dispersed throughout the present catalyst material, which agreed well with the results of STEM. 
In order to elucidate the surface electronic state of Pt species on the as-obtained sample, the XPS experiments were performed and the results were shown in Fig. 2. From the core-level spectrum of $\mathrm{Pt} 4 \mathrm{f}$, the Pt element exists in two types of chemical environments after reduction treatment. A couple of peaks located at binding energies of 74.5 and $71.2 \mathrm{eV}$ were observed, which were ascribed to the $\mathrm{Pt}^{0}$ reported on the $\mathrm{C}^{24}$. Furthermore, the other pair of $\mathrm{Pt} 4 \mathrm{f5} / 2$ and $\mathrm{Pt} 4 \mathrm{f7} / 2$ located at higher binding energies of 75.9 and $72.7 \mathrm{eV}$ was the signal of $\mathrm{PtO}$ or $\mathrm{Pt}(\mathrm{OH})_{2}$. The $\mathrm{Pt}^{0} /\left(\mathrm{Pt}^{0}+\mathrm{Pt}^{2+}\right)$ area for the $\mathrm{Pt} / \mathrm{C}$ catalyst was $68.8 \%$, verifying that most of the $\mathrm{Pt}$ precursor were transformed into $\mathrm{Pt}^{0}$ after reduction treatment.

Effect of temperature on product distribution

The influence of reaction temperature on product distribution was first examined by varying the temperature from 300 to $480{ }^{\circ} \mathrm{C}$ for $4 \mathrm{~h}$ with the addition of $10 \mathrm{wt} . \%$ catalyst (Pt/C/biocrude) and $8 \mathrm{MPa} \mathrm{H}_{2}$ based on the optimization of parameters for the hydrotreatment of algal biocrude ${ }^{13}$. For the hydrogen replacement experiments, at each reaction temperature, after $2 \mathrm{~h}$ of reaction, the gas products in the reactor were vented, and the reactor was charged with $8 \mathrm{MPa}$ fresh $\mathrm{H}_{2}$; the other parameters were kept the same as in the non- $\mathrm{H}_{2}$ replacement experiments. As expected, three products, oil, solid residue, and gas, were produced during this hydrotreatment process. Fig. 3 provides all the results.

For the non- $\mathrm{H}_{2}$ replacement experiments, the treated bio-oil yield increased from 93.4 to $67.6 \mathrm{wt} . \%$ as the temperature increased from 300 to $480{ }^{\circ} \mathrm{C}$, as macromolecules were easily cracked into smaller macromolecules and finally gases at high temperatures. The same result was also observed for the hydrotreatment of the biocrude fraction of crop straw in tetralin ${ }^{10}$, and the yield from the hydrotreatment of pure biocrude also varied as a function of temperature ${ }^{8}$. A higher treated bio-oil yield was always achieved when the algal biocrude was hydrotreated in tetralin ${ }^{10}$ than when treated in supercritical water or with pure biocrude alone ${ }^{14}$, indicating that tetralin was beneficial for liquid product production as it suppressed coke and gas formation, as proved by a previous study that processed the biocrude fraction of crop straw in tetralin ${ }^{10}$. As expected, the gas yield increased from 3.5 wt. $\%$ at $300{ }^{\circ} \mathrm{C}$ to 27.7 wt. $\%$ at $480{ }^{\circ} \mathrm{C}$. A rapid increase in gas yield was found upon increasing the temperature from 400 to $450{ }^{\circ} \mathrm{C}$ as gasification was significantly accelerated in this temperature range, which was consistent with the significant reduction in the treated biooil yield. The gas yield produced at $400{ }^{\circ} \mathrm{C}$ when the biocrude was processed in tetralin was lower than those obtained when biocrude was produced in supercritical water or with pure biocrude alone ${ }^{18}$, indicating that tetralin suppressed the gasification reaction by stabilizing the oil intermediates. The gas products primarily comprised unreacted $\mathrm{H}_{2}$ and $\mathrm{CH}_{4}, \mathrm{CO}, \mathrm{CO}_{2}$, and $\mathrm{C}_{2-5}$ hydrocarbons ${ }^{12-18}$, together with denitrogenation, desulfurization, and deoxygenation products. The solid residue yield initially decreased from $3.7 \mathrm{wt} . \%$ at $300{ }^{\circ} \mathrm{C}$ to 1.9 wt. $\%$ at $400{ }^{\circ} \mathrm{C}$ and increased again with further increasing temperature. At $300{ }^{\circ} \mathrm{C}$, some of the high-molecular-weight compounds could not be totally cracked into smaller compounds, and thus, a large amount solid residue was produced. Increasing the temperature between 300 and $400{ }^{\circ} \mathrm{C}$ promoted the cracking reaction of high-molecular-weight compounds. At temperatures $>400{ }^{\circ} \mathrm{C}$, polymerization prevailed, and a higher solid residue yield was again observed. Higher solid residue production was undesirable as it would cover the catalyst and thus could inactivate the catalyst.

For the $\mathrm{H}_{2}$ replacement experiments, raising the temperature from 300 to $480{ }^{\circ} \mathrm{C}$ reduced the treated bio-oil yield from 96.8 to 73.9 wt.\%, which is consistent with the trend obtained without $\mathrm{H}_{2}$ replacement. Interestingly, however, the treated bio-oil yield generated with $\mathrm{H}_{2}$ replacement was always higher than that generated without $\mathrm{H}_{2}$ replacement at the same reaction temperature due to reduced gas and solid residue yields. The gas product yield during the first $2 \mathrm{~h}$ was always lower than that at a total reaction time of $4 \mathrm{~h}$. This is reasonable, as a longer reaction time would favor gas production at a given temperature. The gas product yield was significantly lower in the second 2-h stage than in the first 2-h stage, as almost no hydrogen was consumed in the second 2-h stage. The same solid yield variation trend was observed as that obtained without $\mathrm{H}_{2}$ replacement, but the solid residue yield was always lower than that obtained without $\mathrm{H}_{2}$ replacement. With $\mathrm{H}_{2}$ replacement, the denitrogenation $\left(\mathrm{HCN}, \mathrm{NH}_{3}\right)$ and desulfurization $\left(\mathrm{SO}_{2}\right)$ products would be removed from the reactor, which would decrease the possibility of catalyst poisoning and thus retard the polymerization reaction of the coke precursor. Therefore, a lower solid residue yield was always 
observed for the $\mathrm{H}_{2}$ replacement experiments than the non- $\mathrm{H}_{2}$ replacement experiments at the same reaction temperature.

Comprehensively considering the yield and quality of the treated bio-oil (see Table 2), $400{ }^{\circ} \mathrm{C}$ was chosen as the temperature for subsequent optimization of the hydrotreatment parameters.

Effect of time on the product distribution

The influence of reaction time on product distribution was examined at $400{ }^{\circ} \mathrm{C}$ with the addition of $10 \mathrm{wt} . \%$ catalyst (Pt/C/biocrude) and $8 \mathrm{MPa}_{2}$ for $1,2,4,6$, and $8 \mathrm{~h}$. For the $\mathrm{H}_{2}$ replacement experiments, the gas products in the reactor were vented, and the reactor was subsequently charged with fresh $\mathrm{H}_{2}$; this process was performed every $2 \mathrm{~h}$ for total reaction times of 4,6 , and $8 \mathrm{~h}$ and every 0.5 and $1 \mathrm{~h}$ for total reaction times of 1 and $2 \mathrm{~h}$, and the other parameters were kept the same as in the non- $\mathrm{H}_{2}$ replacement experiments. Fig. 4 provides all the results.

For the non- $\mathrm{H}_{2}$ replacement experiments, time had less of an effect on product distribution than did temperature. Extending the time from 1 to $4 \mathrm{~h}$ gradually reduced the treated bio-oil yield from 92.6 to 86.2 wt.\% as a longer reaction time favored the cracking of macromolecules to smaller ones. Further extending the time had almost no effect on the product distribution, as the reaction was thermodynamically controlled at a reaction time of [?]4 h. A treated bio-oil yield of $83.7 \mathrm{wt} . \%$ was observed when the same algal biocrude was treated at $400 \operatorname{degC}$ for $2 \mathrm{~h}$ in tetralin with $10 \mathrm{wt} . \%$ added $\mathrm{Ru} / \mathrm{C}$, indicating that external hydrogen was necessary to obtain a higher treated bio-oil yield ${ }^{21}$. The gas product yield increased from 6.8 to 10.9 wt.\% as the reaction time increased from 1 to $4 \mathrm{~h}$ and exhibited almost no variation with further extension of the reaction time. The solid residue yield consistently increased from 0.6 to $4.5 \mathrm{wt} . \%$ as the reaction time increased from 1 to $8 \mathrm{~h}$, indicating that the polymerization reaction always existed during the reaction. The solid residue yield produced at $2 \mathrm{~h}(1.1 \mathrm{wt} . \%)$ was markedly lower than that generated under the same reaction conditions without the addition of external hydrogen ${ }^{25}$, indicating that the hydrogen source played a very important role in the suppression of solid residue formation during the hydrotreatment process.

For the $\mathrm{H}_{2}$ replacement experiments, extending the time from 1 to $8 \mathrm{~h}$ reduced the treated bio-oil yield from 94.4 to $87.6 \mathrm{wt} . \%$, which is consistent with that trend produced without $\mathrm{H}_{2}$ replacement. Interestingly, however, the treated bio-oil yield produced with $\mathrm{H}_{2}$ replacement was always higher than that without $\mathrm{H}_{2}$ replacement at the same reaction time due to reduced gas and solid residue production. The total gas yield increased from 5.1 to 9.5 wt.\% with increasing time from 1 to $4 \mathrm{~h}$. Further extending the time had almost no effect on the gas yield. The total gas yield was never higher than that produced without $\mathrm{H}_{2}$ replacement at the same total reaction time, as only a small amount of hydrogen was consumed after the first round of $\mathrm{H}_{2}$ replacement. The solid residue yield presented the same trend as in the non- $\mathrm{H}_{2}$ replacement experiments, increasing from 0.1 to $2.3 \mathrm{wt} . \%$ as the reaction time increased from 1 to $8 \mathrm{~h}$. A lower solid residue yield was also achieved relative to that produced without $\mathrm{H}_{2}$ replacement at the same reaction time due to removal of denitrogenation, deoxygenation, and desulfurization products.

Effect of $\mathrm{H}_{2}$ replacement frequency on the product distribution

The influence of $\mathrm{H}_{2}$ replacement frequency on the product distribution was examined at 400 degC for a total reaction time of $6 \mathrm{~h}$ with $10 \mathrm{wt} . \%$ added catalyst (Pt/C/biocrude) and $8 \mathrm{MPa} \mathrm{H}_{2}$. Every 3, 2, 1.5, 1.2, and $1 \mathrm{~h}$, the gas products in the reactor were vented, and the reactor was charged with fresh $\mathrm{H}_{2}$. Fig. 5 presents all the results.

For the given time of $6 \mathrm{~h}$, increasing the $\mathrm{H}_{2}$ replacement frequency from 1 to 5 times gradually increased the treated bio-oil yield from 86.1 to 91.0 wt.\%, although this yield increase was small, because the gas and solid residue production was reduced. The more frequent replacement was, the shorter the gas products stayed in the reactor, and the lower the possibility of catalyst poisoning. As expected, the yields of gas and solid residue products consistently decreased with increasing $\mathrm{H}_{2}$ replacement frequency. The gas products were mainly produced before the first round of $\mathrm{H}_{2}$ replacement due to prevailing denitrogenation, deoxygenation, and desulfurization reactions at this stage. The solid residue yield was reduced from 2.4 to $1.6 \mathrm{wt} . \%$ as the 
$\mathrm{H}_{2}$ replacement frequency increased from 1 to 5 times at a given total reaction time of $6 \mathrm{~h}$. That is, if the gas products were removed from the reaction system as soon as possible, they would not poison the catalyst, and secondary reactions with the oil would be avoided, thus prolonging the activity of the catalyst for the hydrogenation reaction. Correspondingly, a lower gas and solid yield and higher treated bio-oil yield would be achieved.

Characterization of the algal biocrude and treated bio-oils

\section{Physical properties}

The algal biocrude had a density of $1.05 \mathrm{~g} / \mathrm{cm}^{3}$, viscosity of $21.80 \mathrm{mpa} . \mathrm{s}$, moisture of $2.13 \mathrm{wt} . \%$, total acid number (TAN) of $47.10 \mathrm{mgKOH} / \mathrm{g}$, and freezing point of $-8.4 \mathrm{degC}$, which agreed with a previous study ${ }^{21}$. In contrast, the treated bio-oil was found to have approximately 1.32-2.34 wt.\% moisture depending on the hydrotreatment conditions. The density of the treated bio-oil varied between 0.88 and $0.95 \mathrm{~g} / \mathrm{cm}^{3}$, smaller than that of the blended biocrude and tetralin feedstock $\left({ }^{\sim} 1.02 \mathrm{~g} / \mathrm{cm}^{3}\right)$. The viscosity of the treated bio-oil varied from 8-18 mpa.s, and raising the temperature and extending the time reduced the viscosity of the treated bio-oil. A much lower TAN of the treated bio-oil was also found, which varied between 4 and 13 $\mathrm{mgKOH} / \mathrm{g}$ due to the removal of acidic compounds. The freezing point of the treated bio-oil was reduced to -14-22 degC which is similar with -20 \# diesel.

\section{Elemental analysis}

Table 2 provides the elemental composition, $\mathrm{H} / \mathrm{C}$ molar ratio, and HHV of the alga, biocrude, and treated bio-oils generated under different reaction conditions. Approximately $60 \%$ of the N, $77 \%$ of the S, and $40 \%$ of the $\mathrm{O}$ that were originally contained in the alga were converted into the biocrude during the HTL process at 350 degC. Thus, the biocrude had a certain amount of $\mathrm{N}$ (52541 ppm), O (9.04 wt.\%), and S (5180 $\mathrm{ppm}$ ). The addition of tetralin to the biocrude at a mass ratio of $50 \%$ halved the $\mathrm{N}, \mathrm{S}$, and $\mathrm{O}$ contents of the biocrude. Under all experimental conditions examined, the treated bio-oil always had a higher $\mathrm{C}$ content and lower $\mathrm{H}, \mathrm{N}, \mathrm{O}$, and $\mathrm{S}$ contents than did the algal biocrude and tetralin blend, implying that deoxygenation, denitrogenation, and desulfurization took place during the hydrotreatment process.

For the non- $\mathrm{H}_{2}$ replacement experiments, the $\mathrm{C}$ content consistently increased from 84.99 wt.\% at $300 \mathrm{degC}$ to $89.75 \mathrm{wt} . \%$ at $480 \mathrm{degC}$. A slight increase in $\mathrm{H}$ content was found as the temperature increased from 300 to $350 \operatorname{deg}$. However, a further elevation in temperature gradually reduced the $\mathrm{H}$ content of the treated bio-oil. Hydrogenation and dehydrogenation reactions took place simultaneously during the hydrotreatment process. Heat is released in the hydrogenation reaction; thus, a lower temperature is favorable for the occurrence of this reaction. At temperatures $>350 \mathrm{deg}$, dehydrogenation reactions prevailed, and more aromatics (see Table 3) were formed ${ }^{25}$, thus decreasing the $\mathrm{H}$ content of the treated bio-oil. The reduced $\mathrm{H} / \mathrm{C}$ molar ratio of the treated bio-oil with increasing temperature again proved the increasing aromaticity of the treated bio-oil. The HHV of the treated bio-oil was accordingly reduced from $44.55 \mathrm{MJ} / \mathrm{kg}$ at $350 \mathrm{degC}$ to 41.60 $\mathrm{MJ} / \mathrm{kg}$ at $480 \operatorname{deg} \mathrm{C}$. The $\mathrm{S}$ content of the treated bio-oil consistently decreased from $477 \mathrm{ppm}$ at $300 \operatorname{deg} \mathrm{C}$ to $2 \mathrm{ppm}$ at $480 \mathrm{degC}$, indicating that a higher temperature was favorable for the desulfurization reaction. The $\mathrm{N}$ and $\mathrm{O}$ contents also decreased from $2.19 \mathrm{wt} . \%$ and $22448 \mathrm{ppm}$ at $300 \mathrm{degC}$ to 0.70 wt. $\%$ and $6778 \mathrm{ppm}$ at $480 \mathrm{deg}$. However, a further increase in temperature increased the $\mathrm{O}$ and $\mathrm{N}$ contents of the treated bio-oil, possibly due to the secondary reaction of deoxygenation and denitrogenation products with the bio-oil at the severe temperature of $480 \mathrm{degC}$, indicating that severe temperatures would not guarantee obtaining treated bio-oil with lower concentrations of $\mathrm{N}$ and $\mathrm{O}$. The same variation trend as a function of temperature was observed for the elemental composition of the biocrude fraction of crop straw treated in tetralin with added $\mathrm{Pt} / \mathrm{C}$ and high-pressure $\mathrm{H}_{2}{ }^{26}$.

For the $\mathrm{H}_{2}$ replacement experiments, the $\mathrm{C}, \mathrm{H}, \mathrm{N}, \mathrm{O}$, and $\mathrm{S}$ contents presented the same variation trend as in the non-hydrogen replacement experiments. Generally, the treated bio-oil had higher concentrations of $\mathrm{C}$ and $\mathrm{H}$ and lower concentrations of $\mathrm{N}, \mathrm{O}$, and $\mathrm{S}$ than did treated bio-oils produced without hydrogen replacement, indicating that the removal of denitrogenation, deoxygenation, and desulfurization products avoided their secondary reactions with the bio-oil. The $\mathrm{S}$ content of the treated bio-oil generated at 480 
$\operatorname{deg} \mathrm{C}$ was $0 \mathrm{ppm}$. However, the $\mathrm{N}$ content of the treated bio-oil generated at $450 \mathrm{deg} \mathrm{C}$ was $3122 \mathrm{ppm}$, indicating that $\mathrm{N}$ was more difficult to remove than $\mathrm{S}$. Sharp reductions in $\mathrm{N}, \mathrm{O}$, and $\mathrm{S}$ concentrations were found as the temperature increased from 300 to $400 \mathrm{deg} C$ regardless of $\mathrm{H}_{2}$ replacement, indicating that denitrogenation, deoxygenation, and desulfurization reactions mainly happened in this temperature range. The treated bio-oil generated at 350-480 $\operatorname{deg} \mathrm{C}$ with $\mathrm{H}_{2}$ replacement always possessed a higher $\mathrm{H} / \mathrm{C}$ molar ratio than did that generated without hydrogen replacement, indicating that the hydrogenation reaction was promoted with hydrogen replacement. The HHV of the treated bio-oil produced with hydrogen replacement was always higher than that produced without hydrogen replacement.

Increasing the reaction time increased the $\mathrm{C}$ concentration and decrease the $\mathrm{H}, \mathrm{O}, \mathrm{N}$, and $\mathrm{S}$ concentrations of the treated bio-oil under $\mathrm{H}_{2}$ replacement or non- $\mathrm{H}_{2}$ replacement conditions. Higher $\mathrm{H}$ concentrations and lower $\mathrm{C}, \mathrm{O}, \mathrm{N}$, and $\mathrm{S}$ concentrations in the treated bio-oil were observed with hydrogen replacement than under non-hydrogen replacement conditions, again indicating that $\mathrm{H}_{2}$ replacement was helpful for hydrogenation reactions and the removal of $\mathrm{N}, \mathrm{O}$, and $\mathrm{S}$ in the bio-oil. A sharp reduction in $\mathrm{S}$ concentration was observed as the time was extended from 1 to $4 \mathrm{~h}$ for both $\mathrm{H}_{2}$ replacement and non-hydrogen replacement reactions. Further extension of the reaction time only slightly reduced the $\mathrm{S}$ concentration. The $\mathrm{S}$ concentrations of the treated bio-oil generated at reaction times of 6 and $8 \mathrm{~h}$ were almost the same regardless of $\mathrm{H}_{2}$ replacement, indicating that desulfurization reached equilibrium at 400 degC. A slight reduction in $\mathrm{N}$ concentration was found as the reaction time was extended from 1 to $2 \mathrm{~h}$ for both non-hydrogen replacement and hydrogen replacement reactions. A sharp reduction in $\mathrm{N}$ concentration was found as the reaction time increased from 2 to $4 \mathrm{~h}$ for both non- $\mathrm{H}_{2}$ replacement and $\mathrm{H}_{2}$ replacement reactions. Small variations in the $\mathrm{O}$ concentration of treated bio-oil were observed as the reaction time was extended from 1 to $8 \mathrm{~h}$ for both non- $\mathrm{H}_{2}$ replacement and $\mathrm{H}_{2}$ replacement reactions as the deoxygenation product $\mathrm{H}_{2} \mathrm{O}$ was difficult to remove from the reactor because most of the $\mathrm{H}_{2} \mathrm{O}$ existed in the liquid state. The $\mathrm{H} / \mathrm{C}$ molar ratio and $\mathrm{HHV}$ of the treated bio-oil also decreased with increasing reaction time regardless of $\mathrm{H}_{2}$ replacement.

Increasing the number of $\mathrm{H}_{2}$ replacement times decreased the $\mathrm{C}, \mathrm{N}, \mathrm{O}$, and $\mathrm{S}$ concentrations and increased the $\mathrm{H}$ concentration of the treated bio-oil. The greater the number of $\mathrm{H}_{2}$ replacement times was, the lower the $\mathrm{N}, \mathrm{O}$, and $\mathrm{S}$ contents of the treated bio-oil. That is, the denitrogenation, desulfurization, and deoxygenation products would be removed as rapidly as possible by increasing the number of $\mathrm{H}_{2}$ replacement times, avoiding secondary reactions with the bio-oil and decreasing the possibility of poisoning the catalyst. The N, S, and $\mathrm{O}$ concentrations were reduced by $68 \%, 49 \%$, and $24 \%$ as the number of $\mathrm{H}_{2}$ replacement times increased from 1 to 5 times, indicating that the number of $\mathrm{H}_{2}$ replacement times had a greater influence on the $\mathrm{N}$ concentration of the treated bio-oil than on the concentrations of $\mathrm{S}$ and $\mathrm{O}$. The $\mathrm{H} / \mathrm{C}$ molar ratio and $\mathrm{HHV}$ of the treated bio-oil also increased with increasing number of $\mathrm{H}_{2}$ replacement times due to the acceleration of hydrogenation reactions.

\section{$G C-M S$ analysis}

Comprehensive GCxGC-TOF-MS analysis was employed to analyze the molecular composition of the biocrude and treated bio-oils produced under different reaction conditions. Fig. S2-6 show the results. The dense dots on the two-dimensional chromatogram represent different compounds with different boiling points and polarities. The advantage of using GCxGC-TOF-MS is that compounds with similar properties typically stay together in a specific area and avoids co-eluting peaks. It should be noted that compounds with a boiling point $>300 \operatorname{deg} \mathrm{C}$ might not have been detected as the inlet temperature was set at $300 \operatorname{degC}$. Furthermore, compounds with a retention time $<240 \mathrm{~s}$ could also not be detected due to the $240 \mathrm{~s}$ solvent delay. To more intuitively explain the relative proportion of substances in treated bio-oil, one-dimensional total ion chromatograms are also presented in Fig. S2-6.

To clearly demonstrate the influence of reaction conditions on the molecular composition of the treated biooil, Table 3 lists the relative content of each compound class in the biocrude and treated bio-oils. Clearly, the biocrude contained a significant quantity of amide (e.g., N-methyldodecanamide, octadecanamide, and hexadecanamide $)^{18}(26.28 \%)$ and O-containing compounds (11.44\%), and approximately $0.23 \%$ S-containing (e.g., allylphenyl sulfide) compounds were also observed, which was consistent with a previous study ${ }^{17,18}$. 
These compounds are mainly generated from the direct decomposition of proteins, lipids, and carbohydrates in algae or secondary reactions between these decomposition products. Only $6.98 \%$ aromatic hydrocarbons and $23.46 \%$ saturated hydrocarbons were observed in the biocrude. In contrast, after the biocrude was hydrotreated in tetralin, the contents of amides, unsaturated hydrocarbons, and O-containing compounds were reduced, and the contents of aromatic and saturated hydrocarbons increased in the treated bio-oil. The increase in aromatic hydrocarbons is mainly due to the presence of tetralin and its hydrogenation products. The saturated hydrocarbons in the treated bio-oil were mainly composed of n-alkanes starting from $\mathrm{C} 7$, which correspond to many regularly spaced peaks in the one-dimensional total ion chromatograms.

Increasing the temperature increased the aromatic hydrocarbon content and reduced the unsaturated hydrocarbon content in the treated bio-oil, which agreed with the reduced $\mathrm{H} / \mathrm{C}$ molar ratio of the treated bio-oil regardless of $\mathrm{H}_{2}$ replacement. The saturated hydrocarbon content in the treated bio-oil increased as the temperature increased from 300 to $400 \operatorname{deg} \mathrm{C}$ due to the dominant hydrogenation reactions. A further increase in temperature gradually decreased the saturated hydrocarbon abundance in the treated bio-oil due to the acceleration of aromatization at severe temperatures. A sharp reduction in N-containing compounds was also found as the temperature increased from 300 to $400 \operatorname{deg} \mathrm{C}$ regardless of $\mathrm{H}_{2}$ replacement, which was consistent with the $\mathrm{N}$ content observed by the elemental analysis. Zhao et al. showed that amides could be converted to nitrile compounds at approximately $300 \operatorname{deg} \mathrm{C}$ and that the nitrile compounds at $350 \mathrm{deg} \mathrm{C}$ almost completely disappeared and were converted into hydrocarbons, which is consistent with the results of the present study ${ }^{27}$. The N-containing compounds in the treated bio-oil produced at $480 \operatorname{deg} \mathrm{C}$ mainly consisted of hydrazine, carbazole, pyrazole, and naphthylamine; these kinds of compounds were extremely difficult to remove. Alost no S-containing compounds were detected in the treated bio-oil at temperatures above $400 \operatorname{deg} \mathrm{C}$, which agreed with the elemental analysis.

Extending the reaction time increased the aromatic hydrocarbon content and decreased the saturated hydrocarbon and unsaturated hydrocarbon contents, implying that a longer reaction time was also beneficial to aromatization reactions. A higher aromatic hydrocarbon content was always observed for the treated biooil produced without $\mathrm{H}_{2}$ replacement. Increasing the number of $\mathrm{H}_{2}$ replacement times could also decrease the aromatic hydrocarbon and unsaturated hydrocarbon contents and increase the saturated hydrocarbon content of the treated bio-oil. The saturated hydrocarbon content in the treated bio-oil produced with 5 rounds of $\mathrm{H}_{2}$ replacement reached as high as $71.62 \%$.

Overall, the GC-MS analysis agreed with the results of the elemental analysis. $\mathrm{H}_{2}$ replacement was beneficial for reductions in the aromatic and unsaturated hydrocarbon contents and an increase in the saturated hydrocarbon content.

\section{Evidence of the reaction of gaseous products with the bio-oil}

The gaseous products produced from hydrotreatment of biocrude and tetralin blended at a mass ratio of 1:1 at 400 for $6 \mathrm{~h}$ with 10 wt.\% added Pt/C and $8 \mathrm{MPa} \mathrm{H}_{2}$ were analyzed by GCxGC-TOF-MS and GC-TCD at the same time. The relative quantity of each component in the gas products detected by GC-MS is listed in Table S1. GC-TCD analysis indicated that the gaseous products were largely composed of unreacted $\mathrm{H}_{2}$, $\mathrm{CH}_{4}$, and $\mathrm{CO}_{2}$ together with trace amounts of $\mathrm{CO}$ and $\mathrm{C} 2-\mathrm{C} 5$ hydrocarbons, which was consistent with the results produced from hydrotreatment of the biocrude fraction of crop straw in tetralin ${ }^{25}$. A certain amount of $\mathrm{NH}_{3}$ was also detected in the gaseous products by GC-TCD, which was derived from the denitrogenation of $\mathrm{N}$-containing compounds in the biocrude. GC-MS analysis of the gaseous products indicated that a certain amount of N-containing compounds, such as $\mathrm{C}_{2} \mathrm{H}_{4} \mathrm{~N}, \mathrm{C}_{3} \mathrm{H}_{7} \mathrm{~N}$, and $\mathrm{C}_{6} \mathrm{H}_{7} \mathrm{~N}$ rather than $\mathrm{NH}_{3}$, also existed. Scontaining compounds such as thiocyanic acid and sulfur dioxide were also observed in the gaseous products. If these $\mathrm{N}$ - and S-containing gases were removed during the reaction, the possibility of reaction between these gases and bio-oil would be avoided.

To verify the reaction between the hydrotreatment gaseous products and bio-oil, the gaseous products produced from hydrotreatment of biocrude and tetralin blended at a mass ratio of $1: 1$ at 400 for $6 \mathrm{~h}$ with 10 wt.\% added $\mathrm{Pt} / \mathrm{C}$ and $8 \mathrm{MPa} \mathrm{H}_{2}$ were used as the gas environment for the treatment of a model oil at 400 
for $4 \mathrm{~h}$ with 10 wt.\% added $\mathrm{Pt} / \mathrm{C}$ and $8 \mathrm{MPa} \mathrm{H}_{2}$. The model was a mixture consisting of $3 \mathrm{~g}$ of $\mathrm{n}-\mathrm{C}_{12}$, $\mathrm{n}-\mathrm{C}_{14}$, and $\mathrm{n}-\mathrm{C}_{16}$ (mass ratio of 1:1:1) and $3 \mathrm{~g}$ of tetralin. After the reaction, the oil products were combined and analyzed by GCxGC-TOF-MS. Fig. 6 presents the total ion chromatograph of this treated model oil. As expected, N- and S-containing compounds were found in the treated model oil products, indicating that reactions between the model oil and the gaseous products occurred. Therefore, $\mathrm{H}_{2}$ replacement could remove some of the N- and S-containing compounds from the reaction system, avoiding secondary reactions of the gaseous products, and thus favored $\mathrm{N}$ and $\mathrm{S}$ removal from the bio-oil.

These above results suggest that a new reactor configuration is needed to realize the in situ removal of gaseous products during the hydrotreatment of biocrude and avoid the loss of oil products at the same time. Fig. S7 shows a schematic diagram of this new reactor configuration suitable for the in situ removal of gaseous products. High-pressure $\mathrm{H}_{2}$ is continuously charged into the reactor during the hydrotreatment of the biocrude, and the gaseous products are carried out of the reactor by $\mathrm{H}_{2}$ together with part of the oil fraction. The flowed out oil fraction is condensed to liquid and flowed back to the reactor. After a certain amount of time, most of the $\mathrm{N}$ - and S-containing compounds are removed from the reaction system, and deep removal of $\mathrm{N}, \mathrm{S}$, and $\mathrm{O}$ would be expected.

\section{Conclusion}

Tetralin is a promising medium for the upgrading of biocrude derived from HTL of microalgae by diluting the biocrude, transforming $\mathrm{H}_{2}$ into active hydrogen, controlling coke formation, and favoring denitrogenation, desulfurization, and deoxygenation. Increasing temperature and time decreased the yield but improved the properties of the treated bio-oil, such as by decreasing the $\mathrm{N}, \mathrm{O}$, and $\mathrm{S}$ contents, regardless of $\mathrm{H}_{2}$ replacement. Raising the temperature and time could also increase the aromaticity of the treated bio-oil by decreasing its $\mathrm{H} / \mathrm{C}$ molar ratio, but a lower aromaticity and higher $\mathrm{H} / \mathrm{C}$ molar ratio of the treated bio-oil were observed for $\mathrm{H}_{2}$ replacement experiments. $\mathrm{H}_{2}$ replacement removed the hydrodenitrogenation, hydrodesulfurization, and hydrodeoxygenation products from the reaction system, avoided their secondary reactions with the oil products and decreased the possibility catalyst poisoning and would thus be favorable for hydrogenation reactions, an increased treated bio-oil yield, and N, O, and $\mathrm{S}$ removal from treated bio-oil. With $\mathrm{H}_{2}$ replacement, $88 \%$ of the $\mathrm{O}, 92 \%$ of the $\mathrm{N}$, and $100 \%$ of the $\mathrm{S}$ originally contained in the algal biocrude were removed under optimal reaction conditions. The treated bio-oil mainly consisted of aromatic and saturated hydrocarbons, making up more than $80 \%$ of the treated bio-oil. However, the $\mathrm{N}$ content of the treated bio-oil was still higher than that of commercially available fossil diesel. Thus, future work should concentrate on the in situ removal of hydrodenitrogenation, hydrodesulfurization, and hydrodeoxygenation products from the reaction system.

\section{Acknowledgments}

We gratefully acknowledge the financial support of the National Natural Science Foundation of China (21776063; 22078082; U1704127), the Scientific and Technological Innovation Team of the University of Henan Province (18IRTSTHN010).

\section{References}

1. Klein-Marcuschamer D, Blanch HW. Renewable fuels from biomass: Technical hurdles and economic assessment of biological routes.AIChE J. 2015;61(9):2689-2701.

2. Raheem A, Prinsen P, Vuppaladadiyam AK, Zhao M, Luque R. A review on sustainable microalgae based biofuel and bioenergy production: Recent developments. J Cleaner Prod. 2018;181: 42-59.

3. Maeda Y, Yoshino T, Matsunaga T, Matsumoto M, Tanaka T. Marine microalgae for production of biofuels and chemicals. Curr Opin Biotechnol . 2018;50:111-120.

4. Kumar G, Shobana S, Chen W-H, Bach Q-V, Kim S-H, Atabani AE, Chang J-S. A review of thermochemical conversion of microalgal biomass for biofuels: Chemistry and processes. Green Chem. 2017;19(1):4467. 
5. Brown T, Duan P, Savage PE. Hydrothermal liquefaction and gasification of microalgaeNannochloropsis sp .. Energy Fuels. 2010; 24:3639-3646.

6. Chen Y, Wu Y, Ding R, Zhang P, Liu J, Yang M, Zhang P. Catalytic hydrothermal liquefaction of D. tertiolecta for the production of bio-oil over different acid/base catalysts. AIChE J. 2015; 61(4):1118-1128.

7. Duan P, Savage PE. Hydrothermal liquefaction of a microalga with heterogeneous catalysts. Ind Eng Chem Res. 2010;50:52-61.

8. Chen NY, Degnan TF Jr, Koenig LR. Liquid fuel from carbohydrate. Chemtech . 1986;16:506-511.

9. Guo Y, Yeh T, Song W, Xu D, Wang S. A review of bio-oil production from hydrothermal liquefaction of algae.Renew Sustain Energy Rev . 2015;48:776-790.

10. Jiang Z, He T, Li J, Hu C. Selective conversion of lignin in corncob residue to monophenols with high yield and selectivity. Green Chem . 2014;16:4257-4265.

11. Yang C, Li R, Cui C, Liu S, Qiu Q., Ding Y., Wu Y., Zhang B. Catalytic hydroprocessing of microalgaederived biofuels: a review.Green Chem. 2016;18:3684-3699.

12. Li Z, Savage PE. Feedstocks for fuels and chemicals from algae: treatment of crude bio-oil over HZSM-5. Algal Res . 2014; 2:154-163.

13. Duan P., Savage P.E. Upgrading of crude algal bio-oil in supercritical water. Bioresour Technol . 2011;102:1899-1906.

14. Duan P, Savage PE. Catalytic treatment of crude algal bio-oil in supercritical water: optimization studies. Energy Environ Sci.2011;4:1447-1456.

15. Duan P, Savage PE. Catalytic hydrotreatment of crude algal bio-oil in supercritical water. Appl Catal B: Environ . 2011;104:136-143.

16. Duan P, Savage PE. Catalytic hydrothermal hydrodenitrogenation of pyridine.Appl Catal B: Environ . 2011;108-109:54-60.

17. Duan P, Bai X, Xu Y, Zhang A, Wang F, Zhang L, Miao J. Catalytic upgrading of crude algal oil using platinum/gamma alumina in supercritical water. Fuel . 2013;109:225-233.

18. Xu Y, Duan P, Wang B. Catalytic upgrading of pretreated algal oil with a two-component catalyst mixture in supercritical water. Algal Res . 2015;9:186-193.

19. Bai X, Duan P, Xu Y, Zhang A, Savage PE. Hydrothermal catalytic processing of pretreated algal oil: a catalyst screening study.Fuel . 2014;120:141-149.

20. Zhao B, Wang Z, Liu Z, Yang X. Two-stage upgrading of hydrothermal algae biocrude to kerosene-range biofuel. Green Chem . 2016;18:5254-5265.

21. Xie L-F, Xu Y-P, Shi X-L, Wang F, Duan P-G, Li S-C. Hydrotreating the distillate fraction of algal biocrude with used engine oil over Pt/C for production of liquid fuel. Catal Today 2020;355:65-74.

22. American Society of Testing Materials. Standard test method for dynamic viscosity and density of liquids by Stabinger Viscometer (and the Calculation of Kinematic Viscosity). ASTM D7042- 20.

23. American Society of Testing Materials. Standard Test Method for Freezing Point of Aviation Fuels. ASTM D2386-19.

24. Lemus J,Bedia J,Calvo L,Simakova IL,Murzin D Y,Etzold BJM,Rodriguez JJ,Gilarranz MA. Improved synthesis and hydrothermal stability of $\mathrm{Pt} / \mathrm{C}$ catalysts based on size-controlled nanoparticles. Catal Sci. Technol . 2016;6(13):5196-5206. 
25. Xu Y-P, Duan P-G, Wang F, Guan Q-Q. Liquid fuel generation from algal biomass via a two-step process: effect of feedstocks. Biotechnol Biofuel . 2018;11:83.

26. Wang Z-C, Duan P-G, Liu X-J, Wang F, Xu Y-P. Hydrotreating the low-boiling-point fraction of biocrude in hydrogen donor solvents for production of trace-sulfur liquid fuel. Ind Eng Chem Res.2019;58(24):1021010223 .

27. Zhao B, Shi Z, Yang X. Upgrading algae biocrude for a low-nitrogen-containing biofuel: compositions, intermediates, and reaction routes. Ind Eng Chem Res . 2017;56:6378-6390.

\section{Hosted file}

Fig. 1.pdf available at https://authorea.com/users/375883/articles/493073-hydro-upgradingof-algal-biocrude-in-tetralin-for-the-production-of-high-quality-liquid-fuel-processintensification

\section{Hosted file}

Fig. 2.pdf available at https://authorea.com/users/375883/articles/493073-hydro-upgradingof-algal-biocrude-in-tetralin-for-the-production-of-high-quality-liquid-fuel-processintensification

\section{Hosted file}

Fig. 3.pdf available at https://authorea.com/users/375883/articles/493073-hydro-upgradingof-algal-biocrude-in-tetralin-for-the-production-of-high-quality-liquid-fuel-processintensification

\section{Hosted file}

Fig. 4.pdf available at https://authorea.com/users/375883/articles/493073-hydro-upgradingof-algal-biocrude-in-tetralin-for-the-production-of-high-quality-liquid-fuel-processintensification

\section{Hosted file}

Fig. 5.pdf available at https://authorea.com/users/375883/articles/493073-hydro-upgradingof-algal-biocrude-in-tetralin-for-the-production-of-high-quality-liquid-fuel-processintensification

\section{Hosted file}

Fig. 6.pdf available at https://authorea.com/users/375883/articles/493073-hydro-upgradingof-algal-biocrude-in-tetralin-for-the-production-of-high-quality-liquid-fuel-processintensification

\section{Hosted file}

Table 1.pdf available at https://authorea.com/users/375883/articles/493073-hydro-upgradingof-algal-biocrude-in-tetralin-for-the-production-of-high-quality-liquid-fuel-processintensification

\section{Hosted file}

Table 2.pdf available at https://authorea.com/users/375883/articles/493073-hydro-upgradingof-algal-biocrude-in-tetralin-for-the-production-of-high-quality-liquid-fuel-processintensification

\section{Hosted file}


Table 3.pdf available at https://authorea.com/users/375883/articles/493073-hydro-upgradingof-algal-biocrude-in-tetralin-for-the-production-of-high-quality-liquid-fuel-processintensification 